\title{
La inmigración latinoamericana y su modelo radiofónico en el País Vasco
}

institucional.us.es/ambitos/

\section{María Teresa Santos Diez}

Universidad del País Vasco

mariateresa.santos@uhu.es

\author{
Jesús Ángel Pérez Dasilva \\ Universidad del País Vasco \\ jesusangel.perez@uhu.es
}

\section{Resumen}

Durante los últimos años han surgido numerosas emisoras desde diferentes lugares de la geografía española destinadas al público latino. Unos medios que dan respuesta a las necesidades de los inmigrantes en cuanto se refiere a información y entretenimiento. El presente artículo se centra en el estudio y análisis de las emisoras de Frecuencia Modulada latinas de la Comunidad Autónoma del País Vasco. Se abordan aspectos referentes a su proceso de creación y la evolución que han experimentado. Además se analizan los contenidos que incluyen en sus parrillas de programación, la publicidad y su presencia en la red.

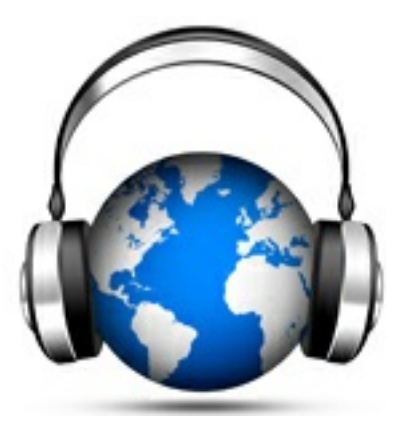

\section{Palabras clave}

Radios latinas, Inmigración, Autonomía Vasca, Música latina, Medios de comunicación, Radio online.

In the last years numerous FM radio stations focused on the Latin-American audience have flourished. These media try to satisfy immigrant's needs regarding information and entertainment. This article highlights the reality of these radio stations in the Basque Country considering aspects such as content and advertising, as well as the strategies that they follow.

\section{Keywords}

Latin-America, Radio Stations, Immigrants, Basque Country, Latin-American Music.

\section{INTRODUCCIÓN}

La llegada masiva de inmigrantes a España ha contribuido de manera decisiva a la creación de medios específicos que den respuesta a sus necesidades. Según datos del Instituto Nacional de Estadística (INE), el año 1981 finalizaba con 198.042 extranjeros en España, cifra que en 2001 se incrementaba hasta los 1.548.941 (3,5\% población total), de los cuales 733.846 tienen una edad comprendida entre los 16 y 44 años. Es decir, en sólo diez años la proporción de extranjeros aumentó un $400 \%$ (INE. Diciembre 2001). Según cifras actualizadas del Padrón Municipal difundidas el 17 de enero de 2014 por el Instituto Nacional de Estadística (INE), la población española alcanza los 41.724 .906 y los inmigrantes son 5.000.258, lo que supone el 10,7 \% del total de la población. Entre las nacionalidades de procedencia destacan los de origen latino con 1.385.472, una cifra que supone el $25,1 \%$ del total, siendo los más numerosos los ecuatorianos (218.189), seguidos de colombianos (181.125), bolivianos (149.949) y peruanos (89.945) (INE: enero 2014). En cuanto al lugar de residencia, fundamentalmente está determinado por motivos laborales, y en consecuencia optan por ciudades con actividad económica elevada que demandan mano de obra como es el caso de Madrid (788.635), Cataluña (69.411) y la Costa Mediterránea (171.191) (INE: enero 2014). Cabe destacar que estos nuevos ciudadanos han contribuido al desarrollo económico experimentado por España durante años. Solo entre los años 2001 y 2006 el efecto positivo de la inmigración 
supuso el 50 \% del crecimiento del PIB (Tedesco 2008: 4). Según Dolado y Vázquez "su presencia aumenta la oferta de trabajo, acentúa el consumo, incrementa la producción y crecen los beneficios empresariales, todo ello sin contar con que aumenta la población" (Dolado y Vázquez 2007, 16, citado en Rey 2008, 2).

Centrándonos en la Comunidad Autónoma Vasca es importante mencionar que entre los años 2004 y 2006 la población extranjera empadronada aumentó un 41\%, hasta alcanzar el 1 de enero de 2006 la cifra de 83.547 personas, que suponía el $4 \%$ de la población, según datos del Instituto Nacional de Estadística (INE: 2006). El 1 de enero de 2013 la población vasca la integraban 2.174.474 habitantes, 10.222 menos que en la misma fecha del ejercicio anterior, de las cuales 148.165 personas eran extranjeras, lo que supone el $8,8 \%$. En cambio, el 1 de enero de 2014 descendían hasta los 140.917, que constituía el 6,4\% de la población.

El colectivo más numeroso en la Autonomía es el de origen latinoamericano con 58.239 personas. Es decir, representan el 40,1 \% de la población extranjera, destacando además que en Vizcaya el 44,1\% de los extranjeros son latinoamericanos, según el Barómetro presentado por Ikuspegi (Ikuspegi 2013:13).

Con el fin de dar respuesta a esta demanda y cubrir el vacío informativo, en el País Vasco surgieron los periódicos gratuitos El Boga (2005) en Vitoria, Nuevo Euskadi (2007) en Bilbao, y el periódico Toumai edición Norte (2008) de Ediciones Toumai. Se trata de pequeñas publicaciones de ámbito local que se ven obligadas a continuos ajustes para poder permanecer en el mercado ante la disminución de la venta de espacios publicitarios, su única fuente de ingresos (Santos y Pérez, 2013: 63). En cuanto a medios audiovisuales, destacan las emisoras en FM Radio Tropical (2001) con presencia en Bilbao, Vitoria-Gasteiz y Donostia-San Sebastián promovida por el Grupo de Comunicación Nervión. También hay que mencionar a Candela Radio que emite desde Bilbao. Otra radio a tener en cuenta es Prisma FM que se pone en marcha en 2009 (Elcorreodigital.es 14/02/09). Son emisoras que han sido innovadoras en adoptar un estilo diferente para dar respuesta a una audiencia nueva. Un público que vive en España pero continúa manteniendo relación con su país de origen donde reside su familia. Su éxito radica en satisfacer sus necesidades, en cuanto se refiere a contenidos de actualidad de ambos lados del Atlántico, así como acompañarles en el tiempo de ocio.

El presente artículo presenta como objetivo el análisis de las emisoras latinas en el País Vasco. Son numerosas las investigadores que estudian el fenómeno de la inmigración latina desde ámbitos diferentes. Destacan autores como Retis (2004) y Benavides y Retis (2005), Ríos (2007) que abordan la inmigración Latinoamérica en prensa española, Llano (2008) hace referencia a la música latina en Barcelona en un entorno cultural. En cuanto se refiere a periódicos gratuitos lo analizan Santos (2008), Martins de Mendoca (2008) y Santos y Pérez (2013), Sabés-Turmo (2009) contempla los medios para la nación latina, González (2010) analiza la participación en radio y las webs para inmigrantes de Gómez-Escalonilla y Campos (2009) entre otros. También en el ámbito internacional mencionamos trabajos como Local radio in the communication environment of ethnic minorities in Britain de Husband y Chouhan, (1985); We Are French Too, but Different Radio, Music and the Articulation of Difference Among Young North Africans in France de Echchaibi (2001); Chinese language media in the United States: Immigration and assimilation in American life con M Zhou, G Cai (2002) entre otros.

La importancia del estudio radica en abordar de manera global el fenómeno de la radio latina tratándola desde el punto de vista de la radio tradicional, aunque no se olvida la posibilidad que hoy día ofrece la tecnología al permitir que cada oyente pueda elegir los contenidos que se adaptan mejor a sus gustos y además presentan el valor añadido de los servicios complementarios de la red (Moreno 2008: 383-395). Por lo tanto, en el estudio se cuantifican y analizan los contenidos y la publicidad y se profundiza en una línea de investigación que no resulta muy atendida por los investigadores y por ello su carácter novedoso.

\section{METODOLOGÍA}

El presente artículo tiene como objetivo analizar las emisoras de Fm destinadas al colectivo latino en la Comunidad Autónoma del País Vasco, entendida como tal la población que ha llegado a España procedente de países latinoamericanos (Sabés-Turmo, 2009: 110). Se aborda el proceso de creación, la evolución que han experimentado, así como la oferta de programación radiofónica de las emisoras latinas y su publicidad. Se trata por tanto de profundizar en el análisis de las emisoras de frecuencia modulada latinas en el País Vasco.

Entendemos como tales aquellas emisoras que emiten unos contenidos dirigidos a un público inmigrante, así 
como información general junto con música latina. El periodo elegido comprende los meses de enero a diciembre de los años 2010 y 2013. Hay que señalar, además, que este texto forma parte de una investigación más extensa realizada en la UPV/EHU sobre los medios de comunicación y el colectivo de inmigrantes. El corpus objeto de estudio queda integrado por las emisoras: Candela Radio, Prisma Fm y Radio Tropical que constituyen el universo total de las emisoras latinas que emiten en la Autonomía. Son representativas en cuanto:

a) Promotores: Radios que surgen desde ámbitos plurales como asociaciones para la integración (el caso de Candela Radio), Instituciones públicas y asociaciones de inmigrantes (como Prisma Fm y del grupo empresarial Nervión que pone en marcha Radio Tropical).

b) Cobertura: quedan reflejados los territorios históricos de Vizcaya (Candela Radio),Álava (Prisma Fm) mientras que Radio Tropical abarca la Autonomía y zonas limítrofes.

c) Contenidos: Emisoras que, a pesar de centrar sus objetivos en lo latino, incluyen otros contenidos generales encaminados hacia la integración y la interculturalidad.

d) Financiación: Candela Radio y Radio Tropical se financian mediante publicidad. Prisma Fm, en cambio, obtiene subvención pública.

Como punto de partida se han planteado las siguientes hipótesis: En primer lugar, y relacionado con los tres primeros objetivos, se plantea la hipótesis de que los contenidos buscan presentar la inmigración como algo positivo, favoreciendo la integración así como la interacción cultural. La segunda hipótesis guarda relación con el cuarto objetivo y plantea que la publicidad está muy especializada para satisfacer las necesidades de ese público tan concreto, destacando el asesoramiento legal, bancario o de seguros. Y por último, estas emisoras recurren a la red como medio complementario, porque es una forma barata y sencilla de llegar a un público muy amplio y en su estrategia cobran valor las redes sociales. Atendiendo a estos parámetros se plantean los siguientes objetivos:

1) Cuantificar la presencia de contenidos específicos destinados a inmigrantes.

2) Comparar y analizar los contenidos de las distintas parillas de programación de las emisoras mencionadas.

3) Analizar la publicidad emitida en las emisoras.

4) Estudiar su presencia en la Red y conocer las características de las versiones digitales de las emisoras

La investigación se planteó mediante una metodología cuantitativa. Una técnica apropiada por su utilidad para analizar y cuantificar contenidos de comunicación según las aportaciones de autores relevantes en esta materia como Holsti (1968), Berelson (1986), Krippendorff (1990) y más recientemente Piñuel (2010). En lo referente al análisis de contenido de sus parrillas de programación se ha establecido una clasificación atendiendo a las secciones representadas:

1) Música. Con presencia de espacios dedicados a los éxitos musicales latinos, además de radio-fórmula con los estrenos musicales del momento.

2) En Magazines presentan música, actualidad, participación de los oyentes, además de entretenimiento, junto con la presencia de grupos sociales, asociaciones y ONGs.

3) Información general incluye los contenidos de actualidad referentes al ámbito local, regional, nacional, así como los acontecimientos que suceden en sus países de origen.

4) Espacio s de integración y cooperación con ofrecen contenidos específicos sobre divulgación encaminados hacia el fomento de valores positivos sobre la inmigración.

En lo que respecta a la publicidad se ha procedido a su análisis mediante una muestra representativa de las cuñas emitidas. Por ello, se ha optado por elegir una semana por estación de lunes a viernes en Radio Tropical 
y Candela Radio (8 semanas en horarios de 7:00 a 22:00 horas), registrando un total de 2.120 cuñas. El planteamiento del trabajo, sigue la misma línea que los contenidos y requiere clasificar cada anuncio en las siguientes categorías: moda, institucional, ocio, bancos, consultorios y aseguradoras, videncia, locutorios y envíos de dinero, peluquerías, restaurantes, alimentación, telefonía, publicidad propia y otros temas variados.

Con el propósito de completar el estudio se recurrió también a una metodología cualitativa siguiendo entre otros autores a Sierra (1998), Berganza (2005), Miguel de (2005) y Ruiz (2005). De modo que las entrevistas semiestructuradas con responsables de las emisoras mencionadas constituyó un elemento clave para completar la información. Asimismo, nos resultó de utilidad el uso de fuentes oficiales como el Instituto Nacional de Estadística (INE), el Observatorio Vasco de Inmigración (Ikuspegi) y el Observatorio de la Diversidad (Mugak). También se recurrió a otras fuentes informativas, tal es el caso de artículos publicados en revistas científicas, bases de datos, páginas web y prensa local. La investigación se completa con el análisis de las web de las emisoras objeto de estudio con el fin de averiguar la oferta informativa y el grado de interactividad y participación con sus audiencias en la Red.

\section{ESTADO DE LA CUESTIÓN}

La llegada masiva de inmigrantes supuso la aparición de medios nuevos capaces de cubrir esas demandas, como ha sucedido con las emisoras de radio latinas. El fenómeno no fue exclusivo de un lugar concreto, sino que proliferó con rapidez por toda la geografía española. En definitiva, nuevas radios para responder a las demandas de nuevos públicos. Con esta finalidad comenzaron a surgir emisoras como es el caso de Radio Gladys Palmera (96.6 FM). Este medio constituye la primera emisora de Fm que responde a este perfil. Empieza sus emisiones en 1999 desde Barcelona por iniciativa de la Asociación Amigos de la Cultura y la Música Caribeña. Ante la precaria situación económica, en el año 2000 pasa a compartir local, gastos e incluso dial con la radio libre Radio Pica que se financiaba mediante la organización de fiestas y cuotas de socios. Una situación que se prolongó hasta 2010, fecha en que el Gobierno de la Generalitat les obliga a dejar de ocupar el dial. Radio Gladys Palmera emitía unoscontenidos dedicados a los ritmos caribeños junto con informativos nacionales e internacionales. En 2006 pasa a ofrecer solo música y en 2009 amplía sus puntos de emisión a Madrid (103.2 FM), Valencia (104.7 FM) y en Internet. Finalmente, en 2010 incluye en su parrilla músicas del mundo, que se puede escuchar en la web www.radiogladyspalmera.com.

Después de esta experiencia han sido muchas las emisoras que han proliferado, principalmente en zonas con mayores concentraciones de extranjeros. En unos casos se trata de pequeñas radios independientes promovidas por los propios inmigrantes con el fin de dar respuesta a sus necesidades informativas. Esto sucede, por ejemplo, en Cataluña con Barcelona latina (2004) y La Bomba (2006), en Sevilla con Radio Integración (2006), La Cultural FM (2007) en Almería, en Bilbao con Radio Candela (2004) o en Vitoria con Radio Prisma (2009) entre otras muchas. Inician su andadura con el objetivo de contribuir a la integración y difusión de su cultura. Con el paso del tiempo pasan a ser radios multiculturales y, a pesar de mantener su espíritu inicial, se dirigen a una audiencia general y además pasan a financiarse en la mayoría de los casos mediante la venta de publicidad comercial.

Destinadas también a esta misma audiencia pero con una finalidad comercial empiezan a surgir nuevos proyectos con emisoras en cadena como es el caso de Canarias. En 1996 un grupo de empresarios promueve Mega latina con puntos de emisión en Las Palmas (93.4 FM), Norte Tenerife (104.3 FM), Tenerife (104.5 FM) y Madrid (105.1 FM), y desde 1997 en la web www.megalatina.fm. En el País Vasco en 2001 se pone en marcha Radio Tropical por iniciativa del grupo Nervión Radio, con una cobertura que alcanza la Autonomía y zonas limítrofes.

Otra opción la forman emisoras de FM generalistas que cambian sus estrategias de mercado para introducirse en este sector, como por ejemplo Radio Pueblo Nuevo (2002) en Madrid y Radio Tentación (1998) con emisoras en Madrid (93.5 FM) y Toledo (91.5 FM) y en la web www.radiotentacion.com. Ambas comenzaron como radios locales generalistas, pero ante la llegada masiva de inmigrantes se reconvierten y especializan sus contenidos hacia esta nueva audiencia. Lo mismo ocurre con la red Top Radio FM. Esta emisora, que se remonta a 1974 con Radio España (97.3 FM), es adquirida en 2001 por el grupo hispano-mejicano Multimedios, que cuenta con reconocida presencia en el mercado con medios impresos y audiovisuales en México. Una operación 
determinante para que en 2002 pasara a emitir contenidos especializados para la población latina. Cuenta con emisoras en Madrid (97.2 FM), Guadalajara (97.0 FM) y Toledo (97.5 FM) y en la web www.topradio.es.

También Top Radio FM llegaba a otras zonas permitiendo a pequeñas emisoras locales conectar con la red con el fin de mantener su programación 24 horas mediante el soporte de una cadena. Un ejemplo lo tenemos en el País Vasco con Canal -3. Es una emisora que inicia su andadura en el año 1983 en Bilbao desde unos locales parroquiales con una finalidad comercial. En 1987 precintan la emisora (Deia, 27/05/1988:16), pero vuelve a emitir como una asociación cultural y una programación de radio-fórmula. En marzo de 1990 el Gobierno vasco obliga a cerrar todas las emisoras que no disponían de concesión de licencia. Unos años más tarde retoma sus emisiones y en 2002 conecta con la cadena Top FM (con el fin de poder ampliar su programación a 24 horas) y pasa a denominarse Canal-3 Top Radio Bilbao (94.2 FM). En 2003 se asocia con Radio Candela (90.3 FM) y adopta la fórmula musical latina y dance. En el 2004 finaliza la sociedad de Candela Radio FM (91.4) y Univerdance Bilbao (90.3 FM). En 2006 abre una nueva etapa de la mano de la cadena nacional Loca FM con puntos de emisión en Bilbao (90.3 FM), Vitoria-Gasteiz (88.8 FM) y Donostia-San Sebastián (95.2 FM). Su programación en esta ocasión mezcla estilos del Dance y Radio-fórmula. Se trata en general de pequeñas emisoras con cobertura local y finalidad comercial, que carecen de concesión administrativa y por lo tanto ilegales. Dada su precaria situación, a lo largo de los años se han ido adaptando a las circunstancias del momento con el fin de intentar sobrevivir.

\section{PERFIL DE LAS EMISORAS LATINAS ANALIZADAS}

En el País Vasco a finales del 2001 inicia su andadura desde Bilbao Radio Tropical (102.9 FM) constituyendo la primera experiencia de radio comercial con una programación musical encaminada hacia los ritmos caribeños como salsa, merengue, bachata, vallenato y pop latino entre otros. En 2002 centra sus contenidos en la integración bidireccional entre el pueblo vasco y la comunidad latina. A últimos del 2003, con apoyo del Grupo de Comunicación Nervión, amplía su cobertura a Vizcaya (102.9 FM), y emprende una política de expansión y llega a Álava (97.7 Fm), Guipúzcoa (101.5 Fm), Logroño-La Guardia (107.3 Fm), Pamplona (102,3 Fm), Barcelona (94,2 Fm) y en la web http://www.radiotropical.fm/ (Véase tabla 1). En su programación incluye contenidos de utilidad con un valor añadido como son boletines horarios, seguimiento del tráfico, información del tiempo, programación específica -como es el caso de la bolsa de trabajo- y asesoría jurídica. Es una emisora que colabora de manera habitual con diferentes instituciones. Asimismo, organiza eventos como festivales, jornadas, conciertos, etc.. Su audiencia, según explican desde Radio Tropical, la integran más mujeres (57 \%) que hombres (43\%). En cuanto a su procedencia, mayoritariamente pertenecen a países latinos (65\%), seguidos de vascos $(30,5 \%)$ y otros $(4,50 \%)$. Su audiencia, según consta en el último estudio realizado en 2009, se estima en119.000 personas por día distribuidos en Vizcaya (54 \%), Álava (25\%), Guipúzcoa (20 \%) y norte de Burgos (1\%) (www.radiotropical.fm).

Candela Radio (91.4 FM) surge promovida por periodistas inmigrantes que cuentan con experiencia previa en sus países de origen. Comenzó su andadura en 2004 en Vizcaya como un proyecto impulsado por la asociación Camino al Barrio. Sus objetivos se centran en divulgar los valores positivos de la inmigración y a la vez difundir la cultura del inmigrante. Para su financiación recurre a la publicidad comercial. También se puede acceder en la web www.candelaradio.fm. A partir de 2009 inicia una nueva etapa y reducen los contenidos latinos para dirigirse al público en general, aunque manteniendo su espíritu inicial de fomento de valores, la integración y la interculturalidad. Asimismo, desarrollan talleres de radio que según Puentes (1) se convirtieron en una herramienta de sensibilización para públicos diversos como es el caso de adolescentes, personas mayores, niños enfocados desde una estrategia comunicacional, intercultural y psicosocial". Unas actividades que cuentan con el apoyo de Instituciones como la Diputación Foral de Bizkai y Ayuntamientos. Su audiencia, según datos facilitados por el medio alcanza los 20.000 oyentes, la constituyen jóvenes españoles con edad comprendida ente entre los 17 y 35 años, además de otro grupo de personas españolas mayores de 55 años (Puentes, 2014).

Otra emisora (2) es Prisma Fm (90.3 FM). Empieza a emitir en febrero de 2008 desde Vitoria-Gasteiz como resultado de la colaboración entre la asociación Colombia-Euskadi y la Diputación de Álava mediante el programa Comunicación para la integración. Para su financiación recibe subvención pública. Responde a la necesidad de crear un espacio de ocio productivo para la juventud inmigrante, que pretende ser una alternativa comunitaria con contenido multicultural (Elcorreo.es 14/02/09). Dan cabida a personas de diferente origen, 
cultura e ideología de la capital alavesa con el fin de mostrar realidades y puntos de vista diferentes. En su programación colaboran asociaciones, ONGs y fundaciones interesadas en comunicar el trabajo que realizan cada día en distintos campos. Después de esta primera etapa, Prisma FM atraviesa un proceso de transformación y busca financiarse mediante publicidad comercial. En 2011 no se cumplen los objetivos esperados y deja de emitir. De nuevo Prisma Radio inicia sus emisiones en octubre de 2012 transmitiendo únicamente online.

En conjunto (3) las emisoras analizadas tratan de difundir valores positivos de la inmigración encaminados básicamente a favorecer la integración, la convivencia entre culturas, así como la toma de conciencia en la igualdad de derechos y deberes, además de respeto por la integridad del ser humano y la diversidad de género (Hernández, 2014).

Tabla 1: Emisoras latinas en la CAPV

\begin{tabular}{|l|l|l|l|}
\hline Emisora & Origen & Frecuencia & Cobertura \\
\hline Emisora & Origen & Frecuencia & Cobertura \\
\hline Radio Tropical & 2001 & $102.9, \quad 89.9$, & Vizcaya, Álava, \\
& & $101.5,96.9$ & $\begin{array}{l}\text { Guipúzcoa, Merindades-BU, } \\
\text { Valle Mena } \\
\end{array}$ \\
& & $104.1,92.3$ & Balmaseda, Pamplona \\
& $102.3,107.3$ & Barcelona, Logroño- Laguardia \\
\hline Candela Radio & 2004 & 91.4 & Vizcaya \\
\hline Prisma Fm & 2009 & $90.3 . \quad$ Desde & Álava \\
& & 2012 online & \\
\hline
\end{tabular}

Fuente: Elaboración propia

\section{ANÁLISIS DE LOS RESULTADOS}

\subsection{Su programación}

Las emisoras analizadas ofrecen unos contenidos que evocan cercanía y nostalgia para las personas que viven aquí y que, en la mayoría de los casos, dejan su familia en el otro lado del Atlántico. Coinciden en incluir locutores de diversas nacionalidades latinoamericanas que representan otros acentos con el fin de enfatizar esa proximidad que acompaña a los oyentes en las actividades diarias. Son espacios de escasa elaboración con mucha música y participación de los oyentes. Cabe destacar que los contenidos se ajustan a unas necesidades concretas y responden a los objetivos planteados por las emisoras. Su éxito radica en ofrecer aquello que su audiencia necesita para estar informado y entretenido.

\subsubsection{La música}

Del análisis de sus parrillas de programación se observa que el tiempo dedicado a la música alcanza porcentajes muy elevados y con una tendencia ascendente durante el tiempo analizado. Prisma FM pasa del 46,5 al $66,80 \%$ y Candela Radio sube del $74 \%$ al $80,68 \%$. En cambio, Radio Tropical desciende del $65,5 \%$ al 56,70 . Coinciden en abordar el pop latino junto con una amplia variedad de géneros musicales del caribe como pueden ser: salsa, el merengue, bachata, reguetón y vallenato. Unos ritmos que cuentan con una gran aceptación internacional y nacional pero que además forman parte de la cultura propia de los latinoamericanos. En las emisoras suena la música de artistas españoles: Alejandro Sanz, Miguel Bosé, Fito \& Fitipaldis, La Oreja De Van Gogh, Roxana, David Bisbal, etc.. en fórmula. Además de figuras internacionales del pop latino entre los que destacan: Maná, Paulina Rubio, Shakira, Juanes, Santana, Diego Torres, Bacilos o Ricky Martin junto con los éxitos del momento. Cabe destacar que estos medios también constituyen una plataforma para el lanzamiento de novedades discográficas de música latina y ritmos caribeños. Por ejemplo, en Radio Tropical destaca el espacio Sabor Tropical con su fórmula de música latina y peticiones musicales. Tampoco se olvidan de la música del recuerdo, como en el programa Lo maravilloso del ayer en Radio Tropical, donde repasan viejas canciones y en cierto modo apelan a la nostalgia. Recurren a los discos dedicados donde se busca la 
participación del oyente que, en directo, felicita a sus familiares y amigos con motivo de bodas, cumpleaños y celebraciones. En esta línea, destaca la emisora Radio Tropical con los espacios Sabor Tropical y Serenata Tropical. De igual modo, Prisma FM tiene en antena Rumba Latina y Salpicón con estilo propio entre otros. Un conjunto de músicas que crean lazos interculturales y a la vez favorecen la difusión de las representaciones folkloricas. Otros espacios musicales, como la radio-Fórmula, alcanza una mayor presencia en el año 2013 en Candela Radio (53,8 \%), Prisma Fm 58,47\% se incrementa como consecuencia de ese cambio de contenidos hacia un público más heterogéneo, mientras que en Radio Tropical $(35,20 \%)$ desciende ligeramente.

Figura 1: Porcentaje de Música

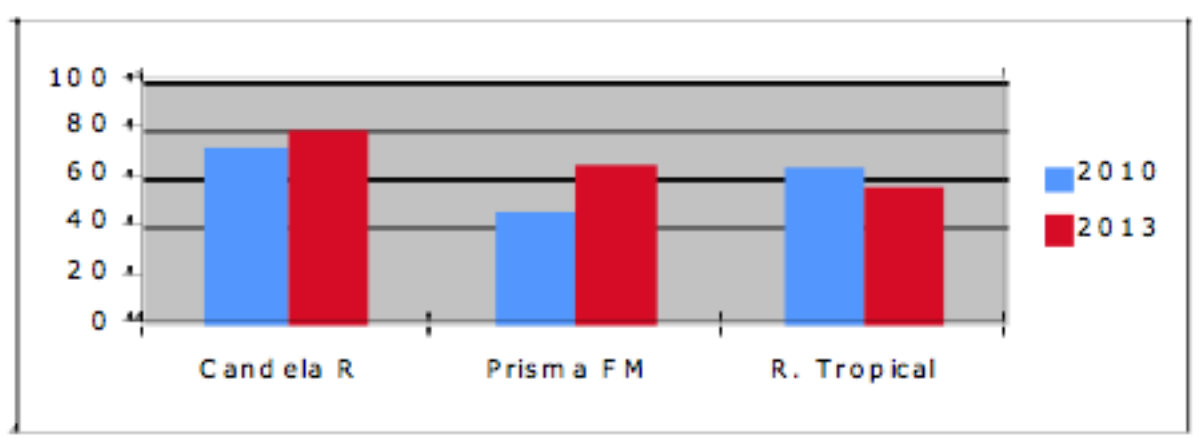

Fuente: Elaboración propia

\subsubsection{Los magazines}

Merecen especial atención los magazines en horarios de mañana y tarde. Constituyen espacios de larga duración abiertos a la actualidad, entretenimiento, información, junto con otros contenidos de utilidad y aportaciones musicales con participación de los oyentes para solicitar sus canciones preferidas y dedicarlas: se lo dedico a todos los oyentes, a vosotros, a mi familia... Tienen cabida las asociaciones de inmigrantes, representantes políticos, junto con profesionales y personas relacionadas con la inmigración con el fin de mostrar las prestaciones que ofrecen los distintos estamentos e instituciones. Abordan el tema de la inmigración desde diversos ámbitos mostrando una visión positiva y divulgando otras culturas y realidades. Un ejemplo es el plan de igualdad Norabide que patrocinan conjuntamente el Gobierno Vasco, algunos ayuntamientos, Integración cultural, Ayuda Internacional y Acción Social entre otros. Ofrecen contenidos cercanos y además útiles para ese amplio colectivo en cuanto se refiere a temas que les afectan de manera directa. Destacan los consejos prácticos en sobre asesoría jurídica -que resuelve dudas en materia de extranjería-, reagrupamientos familiares, ayudas oficiales, vivienda, sanidad, derechos o tramitación de documentos -que van desde cómo montar una empresa a altas de autónomos, derechos, ayudas, prestaciones, y obligaciones principalmente-. En otros casos su utilidad es inmediata, como es el caso de información referida al estado del tráfico, carreteras y previsiones del tiempo. Completan el tiempo con actualidad deportiva, humor, anécdotas, curiosidades, cocina y música. También resulta de interés la bolsa de trabajo que tiene como objetivo mostrar a los oyentes las ofertas de empleo que facilitan tanto empresas como particulares. Unos contenidos que en 2010 suponían en todas las emisoras analizadas la cuarta parte de la programación. No obstante, en 2013, los porcentajes descienden en Candela Radio y Prisma Fm (25\% a $9,40 \%$ y $25 \%$ a $10,40 \%)$. Estos resultados suponen una apuesta por los contenidos musicales en detrimento de otros espacios, que requieren una mayor elaboración. Destacan temas que constituyen éxitos en el ámbito internacional del Pop Latino con programas como Música Urbana, Club de Jazz, Club de la Salsa, Sonidos del Universo y Tendencias. A su vez en Radio Tropical se produce el efecto contrario se incrementan los magazines (25\% a 33,30\%). También destacan los magazines madrugadores como Despertador Tropical, en Radio Tropical, un espacio para comenzar el día con música, humor, participación de los oyentes, información de cercanía con tiempo, tráfico y noticias. 
Figura 2: Porcentaje de Magazines

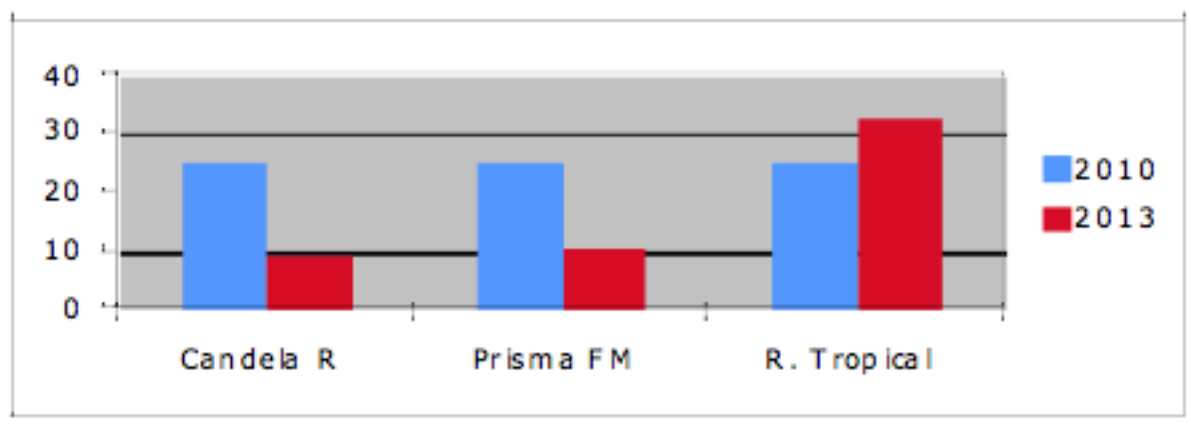

Fuente: Elaboración propia

\subsubsection{Los contenidos informativos}

Los espacios informativos repasan las noticias más destacadas de las capitales de América Latina, junto con la actualidad de sus países de acogida. Tampoco se olvidan del ámbito más cercano, como es el autonómico y local, que les afecta de manera directa. Se ofrecen en Prisma Fm (8,5\% y 6,20\% de la programación) de 7:30 a 8:00 con Más voces. Asimismo, en Radio Tropical ( $8 \%$ y 8,60\%) se emite el informativo diario Noticiero de 8:00 a 8:10 y de 11:00 a 11:10. Esta radio dispone de boletines horarios y a las 12:30 en Info-Vitoria muestra las noticias sociales y culturales que se producen en Álava. De igual modo, incluyen información del tráfico referente a las entradas de las ciudades, así como accidentes y retenciones en tiempo real. También colaboran los conductores ofreciendo la situación del tráfico desde cualquier punto de la geografía. En Candela Radio los contenidos informativos han pasado a ocupar el 10,85 \% de la programación.

Figura 3: Porcentaje de informativos

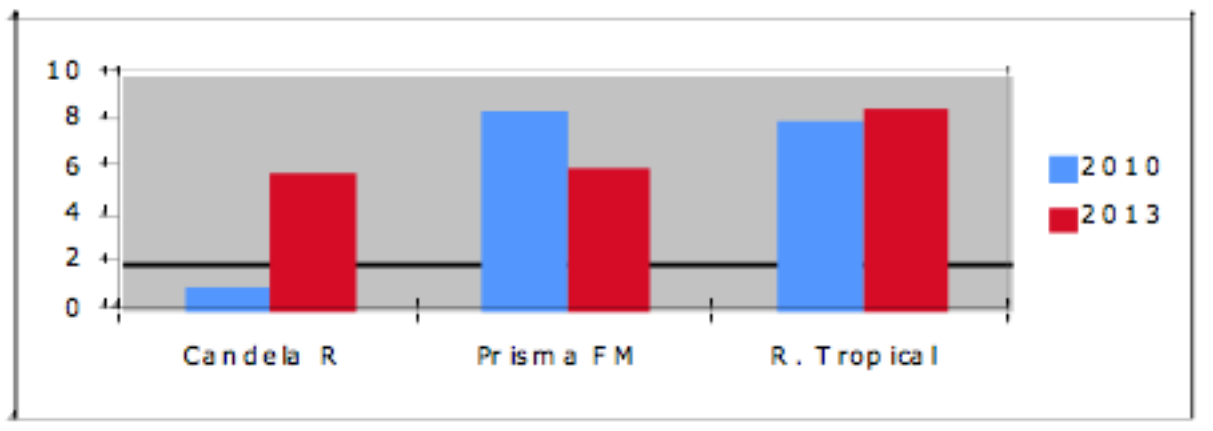

Fuente: Elaboración propia

\subsubsection{Espacios para la integración}

Completan la programación otros contenidos de interés, destacando los dirigidos principalmente a la difusión de valores culturales y actitudes encaminadas a mejorar la integración y colaborar en la normalización. Realizan un recorrido por la cultura de la mano de asociaciones culturales haciendo especial hincapié en lo que atañe a países como Bolivia, Ecuador y Perú entre otros. Estos espacios, por ejemplo, en el caso de Prisma FM suponen el $20 \%$. Tratan de fomentar valores como igualdad de derechos, deberes y respeto entre diferentes, así como programas de índole social abierto a colectivos procedentes de Latinoamérica, Asia, el Magreb y la África Subsahariana con el fin de favorecer la solidaridad e interculturalidad. Un ejemplo lo tenemos en Prisma FM con Txapela y café y en la emisora Candela Radio con La herencia de Colón. Los espacios culturales son en Candela Radio (5\% del total) África mía y La herencia de Colón que repasan la cultura latina. En Radio Tropical también fomentan la integración entre el pueblo vasco y las nuevas comunidades latinoamericanas. Otros programas de interés son el infantil Tropipekes -en Radio Tropical- que incluye adivinanzas, trabalenguas o chistes, así como los temas de misterio en el espacio La otra mirada en Prisma FM. 
http://dx.doi.org/10.12795/Ambitos.2014.i26.13

Tabla 2: Contenidos de las emisoras analizadas

\begin{tabular}{|l|l|l|l|l|l|l|}
\hline & $\begin{array}{l}\text { Candela } \\
\text { R. 2010 }\end{array}$ & $\begin{array}{l}\text { Candela } \\
\text { R. 2013 }\end{array}$ & $\begin{array}{l}\text { Prisma } \\
\text { Fm 2010 }\end{array}$ & $\begin{array}{l}\text { Prisma } \\
\text { Fm 2013 }\end{array}$ & $\begin{array}{l}\text { R. Tropical } \\
2010\end{array}$ & $\begin{array}{l}\text { R. Tropical } \\
2013\end{array}$ \\
\hline & 2010 & 2013 & 2010 & 2013 & 2010 & 2013 \\
\hline Música & 74,00 & 25,88 & 46.50 & 8,33 & 65,00 & 21,50 \\
\hline R. Fórmula & 0,00 & 53,80 & 0,00 & 58,47 & 0,00 & 35,20 \\
\hline Magazines & 25,00 & 9,40 & 25,00 & 10,40 & 25,00 & 33,30 \\
\hline Informativos & 1,00 & 5,85 & 8,50 & 6,20 & 8,00 & 8,60 \\
\hline Cooperación & 0,00 & 5,00 & 20,00 & 16,66 & 0,00 & 0,00 \\
\hline Otros & 0,00 & 0,00 & 0,00 & 0,00 & 2,00 & 1,40 \\
\hline
\end{tabular}

Fuente: Elaboración propia

\section{LA PUBLICIDAD}

Prisma FM en un primer momento carecía de publicidad comercial, dado que desde sus orígenes su financiación se efectúa mediante subvención pública de la Diputación de Álava. No obstante, pasada esta primera etapa inicia un proceso encaminado hacia una radio comercial, aunque sus objetivos no se cumplieron y continua su andadura sin publicidad. Asimismo Cande Radio cuenta con escasa publicidad y su principal fuente de financiación son las aportaciones que realizan entre otras instituciones los Ayuntamientos de Bilbao, Barakaldo, Getxo, Portugalete, BBK, Diputación Foral de Bizlaia entre otros como consecuencia de los convenios de colaboración en las campañas de sensibilización que realizan de manera conjunta.

Dedican atención al tiempo libre y de ocioen actividadesrelacionadascon la música latina en cuanto se refiere a festivales, conciertos y novedades discográficas. Esto supone en Candela Radio un 22,5 \% y un 16,5. Asimismo, en Radio Tropical alcanza un $25 \%$ y un $20 \%$. Del mismo modo, se promocionan algunas discotecas especializadas en bailes latinos, incluso destacando eventos específicos para estos colectivos: Fiesta de la asociación Ecuador. Te invita a.... Fiesta con lo mejor de la bachata 8 euros con Radio Tropical... Discoteca A. te invita a disfrutar con los mejores ritmos latinos, domingos latinos te esperan... En torno a los bailes y la música latina se organizan congresos, talleres de bailes, concursos de carácter nacional o internacional. Unas actividades que popularizan esta cultura entre los inmigrantes latinoamericanos y españoles. Según Isabel Llano, la forma de vivir la fiesta y el baile determina en gran medida las relaciones interculturales que se dan entre la población latina y la población no latina (Llano, 2008:12). También existe otra publicidad relacionada con el envío de dinero -España es el tercer país de la UE que más remesas de inmigrantes envía-. Según datos de la oficina comunitaria de estadística (Eurostat) publicados en diciembre de 2012, los inmigrantes enviaron remesas por un valor de 6.581 millones de euros (expansión.com 10/12/2013). Precisamente, las oficinas bancarias centran sus objetivos en atender estas necesidades, ponen especial atención en captar inmigrantes de Latinoamérica como clientes ofertando productos y servicios específicos. Para este nuevo mercado emergente lanzan libretas de ahorro, tarjetas, seguros de repatriación, accidente, asesoramiento legal, remesas, microcréditos con condiciones especiales de hipotecas, depósitos sostenibles y envío (Véase tabla 3).

Aprovechando este nuevo mercado surgen asesorías y consultorías y aseguradoras especializadas en extranjería que gestionan temas de residencia, nacionalización, reagrupamientos familiares y vivienda entre otros asuntos. Unos porcentajes que se incrementan en Candela Radio (22 \% al 32,3\%) y que disminuyen en Radio Tropical (18,5 \% y 10\%). También destaca una publicidad de pequeños establecimientos locales regentados por los propios inmigrantes. Se trata de una publicidad que hace especial hincapié en la cercanía y lo latino, como sucede por ejemplo en tiendas de ropa, peluquerías: ropa de moda joven con las mejores marcas latinas en... Los mejores peinados, manicura en... Sólo la podrá encontrar en... (Candela Radio 7 \% y Radio Tropical 6 \%). De igual modo, ocurre en restaurantes, bares y tiendas de alimentación. Se distingue la promoción de platos típicos de sus países resaltando los ingredientes, la manera de elaborarlo y el lugar donde se adquiere. Son habituales las alusiones que evocan cercanía, amistad y nostalgia: los mejores platos típicos... El autentico sabor... Productos de tu país, te van a atender como tú te mereces, estás entre amigos, café latino, comida casera, platos variados, autentico sabor de.... En estos sectores acusan un ligero descenso 
en Candela Radio (10 \% y 8,3\%) y en Radio Tropical (17\% y $15 \%)$.

La publicidad institucional está representada fundamentalmente con la divulgación de campañas informativas de servicios que prestan a la inmigración, además de cursos de formación, educación y escolarización principalmente.Suponen en Candela Radio el 16,6 \% y en Radio Tropical el $6 \%$. Se completa con anuncios de videncia en Candela Radio (2\%) y Radio Tropical (5\%), con garantía de resultados inmediatos y soluciones a problemas de trabajo, salud, amor, dinero, etc.

El análisis de la publicidad constata la existencia de un mercado publicitario emergente entre los años 2010 y 2013, que se genera vinculado a actividades relacionadas con la música y los ritmos latinos, como discotecas o revistas. También los establecimientos comerciales regentados por latinos como es el caso de restaurantes, agencias de viaje y supermercados. Otros sectores implicados en captar este mercado son bancos y asesorías. De esta manera, la publicidad atiende a las demandas específicas de la audiencia.

Tabla 3: Publicidad por sectores

\begin{tabular}{|c|c|c|c|c|c|c|}
\hline & $\begin{array}{l}\text { Candela R. } \\
2010\end{array}$ & $\begin{array}{l}\text { Candela R. } \\
2013\end{array}$ & $\begin{array}{l}\text { R. Tropical } \\
2010\end{array}$ & $\begin{array}{l}\text { R. Tropical } \\
2013\end{array}$ & $\begin{array}{l}\text { Prisma } \\
\text { FM } 2010\end{array}$ & $\begin{array}{l}\text { Prisma } \\
\text { FM } 2013\end{array}$ \\
\hline Moda & 7,00 & 0,00 & 10,00 & 0,00 & 0,00 & 0,00 \\
\hline Institucional & 13,50 & 16,60 & 6,00 & 5,00 & 0,00 & 0,00 \\
\hline Ocio & 22,50 & 16,60 & 25,00 & 20,00 & 0,00 & 0,00 \\
\hline Bancos & 10,00 & 8,30 & 15,00 & 15,00 & 0,00 & 0,00 \\
\hline $\begin{array}{l}\text { Consultorias, } \\
\text { seguros }\end{array}$ & 22,00 & 32,30 & 18,50 & 10,00 & 0,00 & 0,00 \\
\hline Videncia & 2,00 & 0,00 & 2,50 & 5,00 & 0,00 & 0,00 \\
\hline $\begin{array}{l}\text { Locutorios } \\
\text { Envios }\end{array}$ & 6,00 & 0,00 & 0,00 & 0,00 & 0,00 & 0,00 \\
\hline Peluquerias & 7,00 & 0,00 & 6,00 & 0,00 & 0,00 & 0,00 \\
\hline $\begin{array}{l}\text { Restaurantes } \\
\text { Alimentación }\end{array}$ & 10,00 & 8,30 & 17,00 & 15,00 & 0,00 & 0,00 \\
\hline Telefonía & 0,00 & 8,30 & 0,00 & 5,00 & 0,00 & 0,00 \\
\hline P. propia & 0,00 & 0,00 & 0,00 & 5,00 & 0,00 & 0,00 \\
\hline Otros & 0,00 & 8,30 & 0,00 & 9,00 & 0,00 & 0,00 \\
\hline
\end{tabular}

Fuente: Elaboración propia

\section{EMISORAS LATINAS ONLINE EN EL PAÍS VASCO}

La aparición y desarrollo de los medios de comunicación online ha cambiado los hábitos de gran parte del público tradicional (lectores, espectadores y oyentes). A medida que se ha incrementado el uso de la Red, la conexión diaria se ha interiorizado como algo normal e Internet se ha convertido así en una pieza imprescindible en las vidas de los usuarios. Tal y como se comenta a lo largo del informe SIE 2013:

"El número de dispositivos con pantalla conectados a Internet no ha hecho más que crecer hasta el punto de que en la mayoría de los hogares es habitual encontrar varios dispositivos con esas características. Este incremento en el número de dispositivos viene acompañado por un incremento en el acceso a contenidos audiovisuales desde ellos; ya el $67 \%$ de los usuarios de smartphone visionan contenidos de esta naturaleza y el $41 \%$ acceden a ellos mediante navegación Web; en el caso de los usuarios de tablet, el $49 \%$ visionan este tipo de contenidos y el 40\% lo hace mediante navegación Web" (Fundación Telefónica, 2013:8). 


\section{Figura 4}

FigUra 1-58. HORAS DEDICADAS A CADA MEDIO DURANTE UNA SEMANA NORMAL EN USUARIOS ENTRE $16 \mathrm{Y}_{24}$ AÑOS (ESPAÑA).

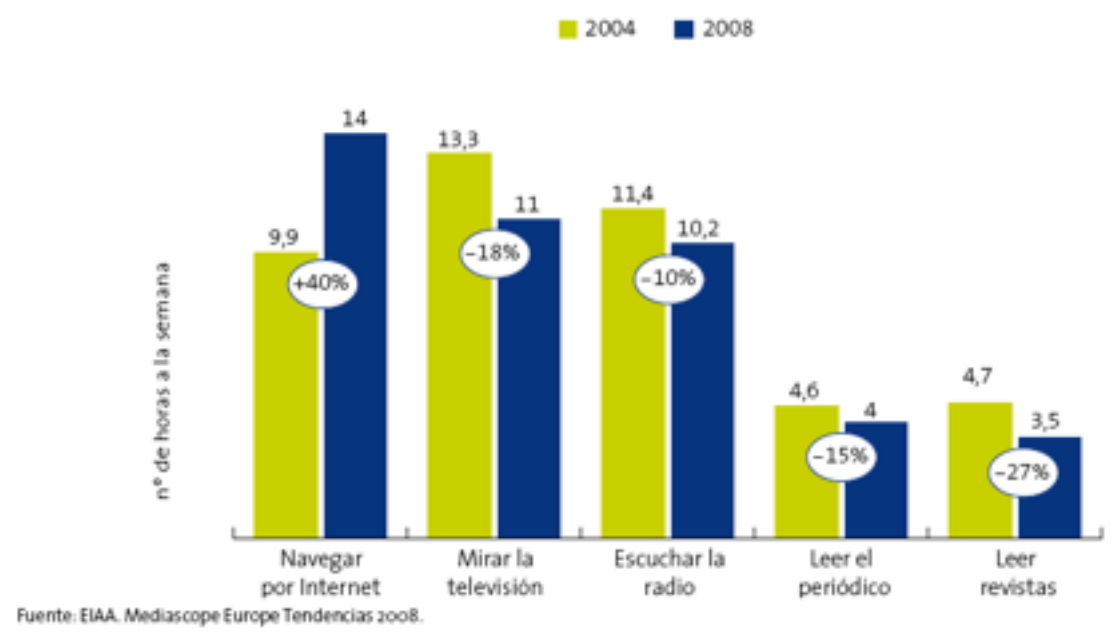

Fuente: Fundación Telefónica, 2009

Desde comienzos de siglo, la Red se ha ido haciendo más participativa gracias a los avances de las TIC y a su popularización, que han originado un cambio en la relación de los usuarios con los medios de comunicación. Sin ir más lejos, gracias a las herramientas de la Web 2.0 los usuarios tienen ahora la posibilidad de participar en la construcción del contenido en la Red -se habla de medios sociales-. Es un contexto de cambio permanente que afecta a todos los sectores, y especialmente al musical. La irrupción de las TIC modifica también la forma en que se distribuye y consume la música. Los cambios comienzan en 1998 con la aparición de los primeros reproductores portátiles de MP3, continúan en 1999 con el sistema de intercambio de archivos P2P Napster, y siguen con el lanzamiento del iPod en 2001. Dos años después se crea el portal de música Myspace y en 2004 aparece en España iTunes -la tienda de canciones online- con un catálogo de 700.000 canciones. Pero es en 2005 y 2006 cuando se produce un cambio fundamental. Esos años surgen Pandora y Last FM, que son sitios online de música en streaming que se adaptan a los gustos del ciberusuario. "Aparecen los llamados sistemas de recomendación o creadores de gustos que deslumbran al combinar las redes sociales con la radio a través de Internet. Estos sistemas de basan en el análisis del comportamiento de los internautas o bien en sus opiniones y evaluaciones, que se estudian para hacer sugerencias a otros visitantes de la web sobre lo que podrá apetecerles escuchar" (Fundación Telefónica, 2009: 70).

Está claro que el modo de consumir contenidos audiovisuales está variando y, por supuesto, esto incluye también el cambio en la forma de escuchar la radio - ya en el 2009 el informe de Telefónica detectó que el $27,1 \%$ de los internautas declaraba escuchar la radio por Internet- por el valor añadido que la Red supone, como por ejemplo la construcción de su propia parrilla de programación. Para Gutiérrez: "Las propuestas online pueden estimular el encuentro siempre y cuando no resulten una copia, más o menos, modernizada de la antena tradicional" (Gutiérrez et al., 2011: 328). De todas formas, en el caso que nos ocupa, el de las emisoras dirigidas a colectivos de inmigrantes, la ventaja es todavía más clara: la radio online elimina la barrera de la distancia y les permite un contacto inmediato y fácil con sus lugares de origen.

Para finalizar este artículo, en este apartado se analizan las emisoras latinas online presentes en Euskadi, sitios online en los que confluye un fenómeno social y otro tecnológico como son la inmigración y el periodismo digital respectivamente. En el País Vasco son cuatro las radios latinas que encontramos online: Radio Tropical Bilbao, Prisma FM Vitoria, Candela Radio Bilbao y Fiesta FM Bilbao. Estos sitios online han sido visitados todos los miércoles de los meses comprendidos entre mayo y octubre de 2013 a media tarde y los resultados se han codificado en una ficha que aborda 25 aspectos agrupados entre la interacción con el emisor, con el mensaje, con el receptor y la creación de contenidos.

Una vez examinada la presencia de estas cuatro emisoras de radio en la Red se puede afirmar que sus sitios online son bastante simples ya que hacen un uso elemental de las posibilidades que les ofrece Internet. En 
general estas páginas ofrecen poco valor añadido para los usuarios. Para estas emisoras el poder escuchar la radio online es una de sus prioridades. Tras un examen detallado de estos canales se constata que Radio Tropical Bilbao, Candela Radio Bilbao y Fiesta FM (aunque en Internet no existe división Bilbao) ofrecen la posibilidad de escuchar la radio a través de Internet. La otra radio, Prisma FM Vitoria, no está disponible.

Candela Radio, Radio Tropical y Fiesta FM se limitan a la posibilidad de consultar la programación online. Esa es básicamente su oferta periodística. Para ser más exactos, Candela Radio Bilbao también ofrece en su página varios titulares que conducen a las noticias de sitios web como el del Ayuntamiento de Bilbao. Pero ahí acaba todo. Por lo tanto queda clara su vocación empresarial-promocional (con contenidos como programación, quienes son los locutores y tarifas publicitarias) y la ausencia de una vertiente periodística sustentada en noticias que se actualicen a menudo. Su punto fuerte no es la información y no alcanzan la categoría ni de portales de entretenimiento. Estos medios no muestran interés en que los usuarios valoren o interactúen con el mensaje, por ejemplo valorando las noticias. La hipertextualidad es mínima, apenas hay enlaces ni contenidos relacionados, y carece de opciones de personalización, como por ejemplo envíos y alertas informativas o RSS. Tampoco hay mapa web, herramientas de búsqueda u opciones de cambiar resoluciones, tamaños, etc. Respecto a la interacción con el emisor, ésta se limita al correo electrónico para contactar con el medio de comunicación. Es la única manera de que los ciberusuarios lleguen al medio.

Los sitios online de estas radios carecen de herramientas de participación como blogs, chats o foros. En cambio, empiezan a estar presentes en sitios de relaciones sociales online como Facebook o Twitter. La más activa es Radio Tropical Bilbao con 5.910 amigos en Facebook y 598 seguidores en Twitter (en febrero de 2013) donde, al contrario que la web, publica contenidos propios y noticias sacadas de otros medios. Candela Radio sólo está presente en la primera plataforma mencionada, al igual que Fiesta FM Bilbao, aunque esta última remite al perfil de Fiesta FM Madrid (con 3.133 seguidores) donde abundan las informaciones sobre actos musicales (fechas, venta de entradas, etc.).

Figura 5

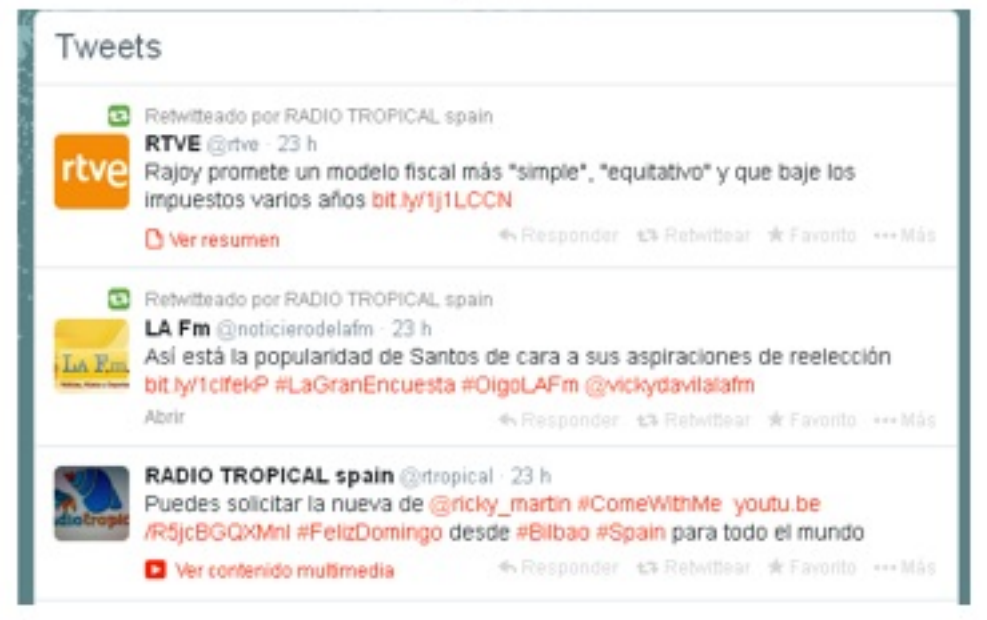

Fuente: https://twitter.com/RTROPICAL

En general, es la adopción de las redes sociales el aspecto más destacable respecto a otras investigaciones como las de Amoedo et al. (2008) o Gutiérrez el al. (2011). Esta última apuntaba que:

"En relación con España, se advierte todavía una falta de definición de estrategias comunicativas de las radios de antena convencional en internet, una situación que afecta de manera especial a las radios musicales" (Gutiérrez et al., 2011: 309).

En este caso, tres años después, los datos indican que se encaminan hacia esa web social de la que hablaba J. Varela (2005) y que las redes sociales empiezan a jugar un papel principal en la relación con sus audiencias. Es a través de estas plataformas como las emisoras latinas incorporan las posibilidades de interacción y participación tan extendidas en el resto de medios.

\section{CONCLUSIONES}


Candela Radio, Prisma FM y Radio Tropicalcontribuyen a la interculturalidad y el intercambio entre la cultura vasca y la de los propios inmigrantes. Muestran la inmigración como un valor positivo, apostando por la eliminación de estereotipos y a su vez buscan la interacción cultural de las distintas comunidades que constituyen la realidad de la sociedad vasca.

En su programación cuentan con locutores profesionales latinos que acompañan a los oyentes con su propio acento, algo que evoca nostalgia por su cultura, tradiciones y música, produciéndose un intercambio cultural entre latinos y españoles, y por lo tanto fomentando la integración. Sus contenidos se caracteriza por presentar espacios de escasa elaboración.

Existe un claro predominio de los contenidos musicales. Las emisoras analizadas coinciden en abordar el pop latino junto con una amplia variedad de géneros musicales del caribe como pueden ser: salsa, el merengue, bachata, reguetón y vallenato. Incluyen, además las listas de éxitos del momento, novedades discográficas y noticias y música en general con el fin de dar respuesta a un público más amplio. Los contenidos musicales se presentan de diversas maneras: discos dedicados con la posibilidad de participar en directo para felicitar a familiares y amigos con motivo de aniversarios, cumpleaños, bodas y celebraciones en general.

Los magazines en horarios de mañana y tarde acusan un descenso en Prima FM y en Radio Candela Radio. Unos resultados suponen una apuesta por los contenidos musicales en detrimento de otros espacios, que requieren una mayor elaboración. A su vez en Radio Tropical se produce el efecto contrario se incrementan los magazines.

Acercan a los oyentes actualidad, entretenimiento e información, junto con otros contenidos útiles como pueden ser: consejos prácticos sobre temas de extranjería, educación, sanidad, además de asesoría jurídica. Se completan los magazines con aportaciones musicales y la participación de los oyentes para solicitar sus canciones preferidas y dedicarlas. Incluyen contenidos de utilidad de uso inmediato como es el tiempo y el tráfico, junto con noticias de ambos lados del Atlántico y de ámbito local, bolsa de trabajo y música latina. Un esquema de programación que se repite en horarios de mañana, mediodía y tarde. Los espacios informativos repasan las noticias más destacadas de las capitales de América Latina, junto con la actualidad de sus países de acogida centrándolo en el ámbito más cercano como es el autonómico y local. Completan la programación otros contenidos de interés, entre los que destacan espacios específicos sobre cooperación dirigidos principalmente a la difusión de valores culturales y actitudes encaminadas a mejorar la integración y colaborar en la normalización. De nuevo está presente ese valor positivo de la inmigración, que contribuye en el intercambio cultural.

En cuanto a la publicidad, en Candela Radio y Radio Tropical ésta se centra en sectores concretos y busca satisfacer las necesidades de esa audiencia. Destaca el tiempo libre y de ocioen actividadesrelacionadascon el ambiente latino en cuanto se refiere a festivales, conciertos y novedades discográficas, discotecas especializadas en bailes latinos, incluso destacando eventos específicos para estos colectivos. También incluyen entidades bancarias que centran sus objetivos en captar inmigrantes de Latinoamérica como clientes. Para ellos destinan servicios específicos como libretas de ahorro, tarjetas, seguros de repatriación, accidente, asesoramiento legal, remesas y microcréditos entre otros. Se completa con publicidad de pequeños establecimientos locales regentados por los propios inmigrantes como tiendas de ropa, peluquerías, restaurantes, bares y tiendas de alimentación. Evocan nostalgia y cercanía a la vez que hacen hincapié en un valor positivo de lo latino y en la cultura.

Respecto a su presencia en la Red, ésta es muy elemental. La interacción social con sus contenidos en el sitio web es mínima y su oferta se limita a la posibilidad de escuchar la radio online. Pero sí se observa un cambio en los últimos tres años. Se trata de la introducción de los sitios de relaciones sociales online como Twitter y Facebook. Este último, especialmente, es es el espacio de participación más común en estas emisoras latinas. Es en estas plataformas donde se aprecia la interacción con su público con contenidos informativos (conciertos, etc.), comentarios de noticias y servicios como información sobre venta de entradas.

\section{REFERENCIAS BIBLIOGRÁFICAS}

ALMIRÓN, N. (2006): "Los valores del periodismo en la convergencia digital: civic journalism y quinto poder". 
Revista latina de comunicación social, 61 (La Laguna, Tenerife). Consultado 2 de abril de 2014 en: http://www.ull.es/publicaciones/latina/200609almiron.htm

AMOEDO, A., MARTíNEZ-COSTA, M. P. Y MORENO, E. (2008): "An analysis of de communication strategies of Spanish comercial music networks on the web: los 40.com, los 40 principales.com, cadena100.es, europafm.es and kissfm.es". The Radio Journal: International Studies in Broadcast and Audio Media, vol. 6, nº 1, pp. 5-20.

BARÓMETRO (2013): Percepciones y actitudes hacia la inmigración extranjera. Bilbao. Ikuspegi.

BAILEY, K. Methods of Social Research (2a ed) (1990). The Free Press, Nueva York. Jankowsi (eds.) (1993). Metodologías cualitativas de investigación en comunicación de masas. Bosch. Barcelona.

BENAVIDES, J.L., Y RETIS, J. (2005): Miradas hacia Latinoamérica: la representación discursiva de los inmigrantes latinoamericanos en la prensa española y estadounidense Palabra Clave, núm. 13, diciembre. Universidad de La Sabana Colombia.

BERELSON, B. (1986): Análisis de Contenido, Akal, Universitaria, Madrid.

BERGANZA, M. R. Y RUÍZ, J.A, Coord, (2005): Investigar en Comunicación. Guía práctica de métodos y técnicas de investigación social en Comunicación, McGraw Hill.

BOWMAN, S. Y WILLIS, C. (2004): We media. The media center at the american press institute. Consultado 2 de abril de 2014 en: http://www.hypergene.net/wemedia/espanol.php

CORREODIGITAL.COM (2009): “La radio desde otro prisma”. Consultado 22 de marzo de 2014 en: http://www.elcorreodigital.com/alava/20090214/cultura/radio-desde-otro-prisma-20090214.htm/

DEIA (1988): Precintan la emisora Canal-3 de Bilbao en su cuarto aniversario".27/5. 16.

DE MIGUEL. R. (2005): La entrevista en profundidad a los emisores y receptores de los medios, en Investigar en Comunicación. Guía práctica de métodos y técnicas de investigación social en Comunicación. Ed. Cejudo, Manuel. Madrid. 251-273.

DÍAZ, J. et al. (2007): El impacto de Internet en los medios de comunicación vascos. Leioa: Servicio editorial de la UPV-EHU.

DIEZHANDINO, P. Y OTROS (2010): Periodismo digital en tiempos de crisis. Un caso de estudio: el tratamiento de la inmigración en los medios. Colección Fundación Telefónica. Ariel.

ECHCHAIBI, N (2001): We Are French Too, but Different Radio, Music and the Articulation of Difference Among Young North Africans in France. International Communication Gazette.

ENCUESTA DE POBLACIÓN ACTIVA (EPA).

ESTUDIO sobre Actitudes sociales de los españoles de la Fundación BBVA (2010):Consultado 14 febrero 2014 en: http://alacant.wordpress.com/2007/08/12).

FUNDACIÓN TELEFÓNICA (2009): Informe La Sociedad de la Información en España 2009 (SIE). Barcelona: Ed. Ariel y Fundación Telefónica. Consultado 2 de marzo de 2014 en: http://www.telefonica.es/sociedaddelainformacion/html/informes_home.shtml

FUNDACIÓN TELEFÓNICA (2013): Informe La Sociedad de la Información en España 2013 (SIE). Barcelona: Ed. Ariel y Fundación Telefónica. Consultado 22 de marzo de 2014 en: http://www.fundacion.telefonica.com/es/arte_cultura/publicaciones/sie/sie2013.htm

FUNDACIÓN ORANGE (2009): Informe eEspaña 2009 sobre el desarrollo de la sociedad de la información. Madrid: Fundación Orange. Consultado 15 de marzo de 2014 en:

http://www.fundacionorange.es/areas/25_publicaciones/publi_251_8.asp 
GONZÁLEZ, P. (2010): Espacios de participación radiofónica e inmigración. El caso rumano, en Revista Latina de Comunicación Social, 65. P: 45-60. La Laguna (Tenerife): Universidad de La Laguna. Consultado 6 de abril de 2014 en: http://www.revistalatinacs.org/10/art/882_UC3M/04_PG_Aldea.html

GÓMEZ-ESCALONILLA, G Y CAMPOS, M. (2009): Espacios de solidaridad en Internet: webs para inmigrantes. En Trípodos, Vol 1. La metamorfosis del espacio mediático. Número extraordinario sobre el V Congreso Internacional Comunicación y Realidad. Barcelona: Blanquerna-Universitat Ramon Llull, pp. 215-217.

GUTIÉRREZ, María et al. (2011): La audiencia juvenil y el acceso a la radio musical de antena convencional a través de internet. En Comunicación y Sociedad, n² 2, p. 305-331. Consultado 22 de marzo de 2014 en: http://www.unav.es/fcom/comunicacionysociedad/es/articulo.php?art_id=398

HOLSTI, R. (1968): Content analysis", en Lindzey, G. y Aronson, E.: The handbook of social Psychology, vol. 2, ResearchMethods, Addison-Wesley, Reading, Mass.

HUSBAND, C., y CHOUHAN, J. (1985); Local radio in the communication environment of ethnic minorities in Britain. New Approaches to the analysis of...

INFORME CENTRO DE ESTUDIOS y Documentación sobre Inmigración, Racismo y Xenofobia (2014): Consultado 22 de marzo de 2014 en: http://www.mugak.eu/gunea/

INFORME OBSERVATORIO VASCO de Inmigración(Ikuspegi). Consultado 22 de marzo de 2014 en: http://www.ikuspegi.org/es/

INSTITUTO NACIONAL DE ESTADÍSTICA (INE). Consultado 22 de marzo de 2014 en: en: http//:www.ine.es KRIPENDORFF, K. (1990): Metodología del análisis de contenido. Teoría y práctica, Paidós Comunicación, Barcelona.

LLANO, I. (2008): "Inmigración y música latina en Barcelona: el papel de la música y el baile en procesos de reafirmación e hibridación cultural”: Revista Sociedad y Economía, Núm. 15, diciembre-sin mes, 2008, pp. 11-36 Universidad del Valle Colombia. Revista Sociedad y Economía Universidad del Valle ColombialSSN (Versión impresa): 1657-6357. Consultado 22 de marzo de 2014 en: http://redalyc.uaemex.mx/src/inicio/ArtPdfRed.jsp? iCve=99612494001.

MARTINS DE MENDOCA, L. (2008): "La presencia de los inmigrantes y del proceso de inmigración en la prensa gratuita barcelonesa: estudio exploratorio”. Ámbitos 17. Sevilla, pp. 147-161.

NIELSEN (2010): Ómnibus Inmigración. The Nielsen Company. Consultado 12 febrero 2014 en: http://es.nielsen.com/trends/est_inmigrantes.shtml

RETIS, J. (2004): "La imagen del otro: inmigrantes latinoamericanos en la prensa nacional española", Sphera Pública, núm. 4, Universidad Católica San Antonio de Murcia España, 119-139.

SABÉS, F. (2009): Los medios de comunicación para la "nación latina" que vive en España. Palabra Clave, 1, 107- 119.

SALVAT, G. Y PANIAGUA, P. (2007): ¿Es esto periodismo, ciudadano?, Estudios sobre el Mensaje Periodístico, vol. 13. Universidad Complutense de Madrid. Pags. 227-246.

SANTOS, T. (2008). Periódicos gratuitos para inmigrantes. Noticias de acá y de allá. Estudios sobre el Mensaje Periodístico, 14, 605-616.

SANTOS, T. y PEREZ, J.A (2013): "Prensa gratuita para inmigrantes en el País Vasco: una lucha por la supervivencia”. Doxa Comunicación, n 14, pp. 59- 73.

SIERRA, R., (1998): Técnicas de investigación social. Teoría y ejercicios, Paraninfo, Madrid. 
TOURAL, C. Y LIMIA, M. (2009): “Los medios de comunicación en Galicia y la web 3.0”, V Congreso Internacional Comunicación y Realidad: La metamorfosis del espacio mediático. Barcelona: Universitat Ramon Llull. Págs. 575-583.

ZHOU, M., y CAI, G. (2002): "Chinese language media in the United States: Immigration and assimilation in American life". Qualitative Sociology, Springer.

VARELA, J. (2005): "Periodismo participativo: El periodismo 3.0”. En: Blogs. La conversación en Internet que está revolucionando medios, empresas y a ciudadanos. Madrid: ESIC.

\section{Breve semblanza de los autores}

María Teresa Santos Diez es doctora en Ciencias de la Información y Profesora Titular de Universidad en la Facultad Ciencias Sociales y de la Comunicación de la UPV/EHU Dpto. Periodismo II. Es autora de artículos como: El desarrollo de la televisión local en Vizcaya (Estudios sobre el Mensaje Periodístico, 2004 La prensa gratuita se expande en España (Telos, 2005). Prensa gratuita para inmigrantes: Noticias de acá y de allá. (Estudios sobre el Mensaje Periodístico, 2008). Las televisiones locales del País Vasco en Internet ( Latina, 2009), La salud en la prensa gratuita especializada. Un fenómeno emergente" ( Estudios sobre el Mensaje Periodístico, 2009). Diarios gratuitos de información general: percepción, hábitos de consumo y preferencias de lectura de los universitarios vascos. (Estudios sobre el mensaje periodístico 2010). Prensa gratuita y jóvenes. Estudio de hábitos de consumo, preferencias y contenidos. (Ámbitos. Revista Internacional de Comunicación 2011). Prensa gratuita para inmigrantes en el País Vasco: una lucha por la supervivencia (Doxa 2012). Además ha publicado una decena de libros entre ellos: Radios comerciales ..Ondas libres (1994), La radio vasca (1999, La prensa gratuita en el País Vasco . (2001), Periodismo Radiofónico (2004), El auge de la prensa gratuita en España (2008), La Televisión local en el País Vasco (2010). La apuesta de Vocento por la prensa gratuita. Nuevas estrategias de mercado (2013).

Jesús Ángel Pérez Dasilva es Doctor en Ciencias de la Información y profesor agregado en la Facultad Ciencias Sociales y de la Comunicación de la UPV/EHU. Dpto. Periodismo II. Leioa (España). Ha publicado artículos como: La comunicación institucional y de servicios. El desarrollo de la televisión local en Vizcaya (Estudios sobre el Mensaje Periodístico, 2004. Las páginas web municipales de las capitales de provincia españolas (Análisi, 2006); El interfaz gráfico de usuario y la orientación a la compra en las revistas de consumo de informática: El caso de Computer Hoy (Zer, 2006); Webs municipales del País Vasco y Navarra: Importancia de la dimensión de servicios y retraso en el aspecto informativo (Estudios sobre el Mensaje Periodístico, 2007); Las televisiones locales del País Vasco en Internet (Revista Latina, 2009); Diarios gratuitos de información general: percepción, hábitos de consumo y preferencias de lectura de los universitarios vascos. (Estudios sobre el mensaje periodístico 2010). Prensa gratuita y jóvenes. Estudio de hábitos de consumo, preferencias y contenidos. (Ámbitos. Revista Internacional de Comunicación 2011). Prensa gratuita para inmigrantes en el País Vasco: una lucha por la supervivencia (Doxa 2012). También es autor del libro La Televisión local en el País $\operatorname{Vasco}(2010)$

(1) Entrevista Miguel Ángel Puentes Bernardino. Director de Candela Radio (3 de junio 2014).

(2) Entrevista personal a D. Jhon Freddy Hernández Ríos representante legal de la Asociación ColombiaEuskadi (16 Marzo 2012 y 22 mayo 2014).

(3) Entrevista personal D. Wilson de Candela Radio (12 de marzo 2012). 
Recibido: 8/7/2014

Aprobado: 1/9/2014 